\title{
Context Effects on Gender Schematic Behavior
}

\author{
Margaret L. Signorella \\ The Pennsylvania State University \\ Irene Hanson Frieze \\ University of Pittsburgh
}

1999

\begin{abstract}
Author Notes
Margaret L. Signorella, Department of Psychology; Irene Hanson Frieze, Department of Psychology.

We would like to thank Sean Forbes, Cynthia L. Frederick, and Carol A. Morgan for their help in coding data.

Correspondence concerning this article should be addressed to Margaret L. Signorella, 25 Yearsley Mill Rd., Media, PA 19063. msignorella@psu.edu.
\end{abstract}




\begin{abstract}
Samples of adolescent girls and of women and men college students were asked to describe in their own words a time in which they had acted in a feminine manner and a time in which they had acted in a masculine manner. These open-ended data were coded for themes, the gender of others present in the situation, and the context of the activity. As predicted, girls and women were more likely than men to mention boys or men being present when acting in a feminine manner. Also as predicted, men were more likely than women or girls to mention girls or women being present when acting in a feminine manner. On the question about acting in a masculine manner, all participant groups' examples were more frequently with men or boys only present, although women's and girls' responses were more strongly in that category than were men's. Further, this tendency was observed more frequently on examples of masculine roles than on examples of aggression. Finally, comparing responses to the questions within gender showed that women mentioned a heterosexual dating context significantly more frequently for the question about feminine than about masculine behavior. Implications of these findings for the measurement of masculinity and femininity are discussed.
\end{abstract}




\section{Context Effects on Gender Schematic Behavior}

Although much attention has been given to the content of gender schemas and the effects of having such schemas upon memory and other cognitive processes (e.g., Deaux \& Lewis, 1984; Ruble \& Stangor, 1986; Liben \& Signorella, 1987), a less investigated question is how gender schemas operate in everyday life contexts. This paper addresses the question of how the social context affects the displays of "feminine" and "masculine" behaviors in both sexes. An open-ended data collection procedure was used that elicited both adolescents' and young adults' reports about when they acted in a masculine and in a feminine way.

This study's methodology is based on the assumption that to understand fully individuals' concepts of masculinity and femininity, one should allow them to describe gender-related situations without prior cueing of certain types of traits and behaviors. The open-ended procedure used does not provide persons with predetermined ideas about how the researcher thinks about gender. The need for more personalized ideas about feminine and masculine behaviors is demonstrated in a number of studies. For example, when Spence and Sawin (1985) asked respondents for descriptions of femininity and masculinity, their descriptions included physical appearance, personality characteristics, cognitive abilities, roles, and social behaviors. Such descriptions are far broader than the aspects typically included in scales purporting to measure "masculinity" and "femininity" (see Signorella and Frieze, 1989)

Spence (e.g., 1993) has further argued that although both sexes possess traits and activity preferences associated with both the same and the other sex, they "use those gender-congruent characteristics they possess to verify and maintain their gender identity" (p. 633). For same-gender characteristics that individuals do not have and other-gender characteristics that they do have, Spence (1993) contended that individuals will downplay their importance in determining their gender identities. Thus, according to Spence, individuals will likely exhibit a variety of both same- and other-gender characteristics, with adults showing no coherent "masculine" or "feminine" theme in their responses, in part because of multiple influences on those behaviors. Deaux and Major (1987) presented a similar model of gender-related behavior in which they argued that concepts of masculinity and femininity are fluid and people display different aspects of the self, depending on the context of the situation.

There is concern, however, that insufficient attention is being given to situational influences. Gilbert (1994) argued that "feminist scholars are in danger of losing gender as a critical 
aspect of context in studies of human behavior" (pp. 539-540). Similar concerns have been expressed by Unger (1993), who noted that in spite of 20-year-old evidence that "[s]ocial circumstances constrain everyone's behaviors" (p. 214), "much of psychology. . .[is] still mired in essentialist views about the differences between women and men" (p. 214)

In the present research, therefore, we examined possible context factors that could influence the display of "masculine" or "feminine" characteristics. The first question we investigated is whether the display of feminine and masculine behavior is dependent upon the gender of others present in the situation. Although those who act "out of role" generally are perceived negatively (e.g., Rasmussen \& Moely, 1986), there are some data indicating that individuals act differently when with similarly-aged girls or women than when with similarly-aged boys or men. For example, research on nonverbal behavior suggests that women are most likely to behave "in role" when in the presence of men and to behave in less stereotyped and more "masculine" ways when they are interacting only with other women, especially women friends (Mayo \& Henley, 1981). Girls are also more likely to use obscene language or "dirty words" when with other girls than with boys (Jay, 1980).

For men, previous research suggests that in-role behavior will occur in the presence of the same gender and out-of-role behavior in the presence of the other gender. Some men have shown a tendency to be most "masculine" in their interactions with men than with women, in terms of displaying aggressive or dominance behavior and fewer warm or expressive behaviors (Vrugt \& Kerkstra, 1984). We would expect similar patterns for boys interacting with male and female peers.

Based on these findings, it is hypothesized that when asked to describe oneself acting in a masculine manner, girls and women will more often than boys and men spontaneously mention girls or women as being present. Male participants, relative to female participants, should more often mention boys or men being present.

The predictions for feminine examples are less clear for girls and women than for boys and men. Empirical data support the idea that men are most often "feminine" with women than men (Weitz, 1976). Similarly, as noted earlier, it appears that women are more likely to behave "in role" in the presence of men (Mayo and Henley, 1981). On the other hand, other research finds both men and women being more expressive and having less rigid postures when interacting with a woman as compared to a man (Davis \& Weitz, 1981). The bulk of the evidence leads to our hypothesis that, when asked to describe oneself acting in a 
feminine manner, girls and women will more often than boys and men spontaneously mention boys or men as present. Boys and men, more than girls and women, are expected to mention females as present.

The last prediction from the research on nonverbal behavior is that heterosexual interest in a young adult sample will also affect behavior. Heterosexual situations appeared to fit Deaux and Major's (1987) criterion for "strong situations," in that they should typically "provide clear and salient cues to appropriate action" (p. 378), which should be consistent with traditional ideas about gender roles. Supporting this logic, Pearson (1985) argued that men and women who are attracted to one another sexually will act in more conventionally "feminine" ways (for women) and "masculine" ways (for men) This result is expected for those participants describing a heterosexual dating context when asked to describe their own behavior--the behaviors will be consistent with their gender.

Finally, the responses of college students when asked to describe their feminine and masculine behaviors were compared to the responses of middle- and high-school-aged students. Several theories predict increases in gender stereotypic behaviors during adolescence (for a summary, see Katz \& Ksansnak, 1994) Thus, context effects are expected to stronger in the young adult sample.

\section{Method}

\section{Participants}

The college student participants were 173 women and 137 men recruited from general psychology classes at the University of Pittsburgh as part of a larger study on gender, career, and family (Signorella and Frieze, 1989). The students received class credit for their participation. The ethnic composition of the sample was $89 \%$ white, $8 \%$ black, and $3 \%$ other ethnicity, according to self-report.

The younger participants were 142 girls and 14 boys, recruited from grades 6 to 12 of a private school, who were part of a larger study on gender and the classroom environment (Signorella, Frieze, \& Hershey, 1996). There were 18 sixth grade girls, 24 seventh grade girls, 19 eighth grade girls, 26 ninth grade girls, 9 ninth grade boys, 19 tenth grade girls, 5 tenth grade boys, 20 eleventh grade girls, and 16 twelfth grade girls. The small number of boys available was due to the fact that the school was just beginning a change from all girls to mixed gender and had only integrated two of the six upper grades. 


\section{Materials}

Participants were given several questionnaires dealing with career and family plans, perceptions of the lives of various men and women, and standard gender-related measures. Included within this package were two open-ended questions. The questions were intended to be parallel, but the wording for the younger participants was simplified. The older students were asked: (1) Describe a time when you acted in a masculine manner. Why did you feel that your actions were masculine in this situation?; and (2) Describe a time when you acted in a feminine manner. Why did you feel that your actions were feminine in this situation? The younger students were asked: (1) Describe a time when you acted like a boy; and (2) Describe a time when you acted like a girl.

\section{Procedure}

The older participants were tested in groups of 5 to 20. One-half the participants received a questionnaire with the masculine question listed first and one-half the questionnaire with feminine question listed first.

The younger participants were tested in their classes by their teachers. All participants received the masculine question first and the feminine question second.

Coding of responses. Three major areas were examined through the coding scheme. First, the gender of others present was coded (males only, both sexes, females only, no one else present, or others present but sex unspecified)

Second, the context given in the example was coded (sexual/dating, with family member, with younger person) Although we originally coded other contexts as well (e.g., business), the additional categories were eliminated due to extremely low frequencies. Because these contexts could overlap, the presence or absence of each was coded. The context codes were only useful in the older sample. The younger participants rarely gave enough details to determine the context of the example.

Third, the content of the example was coded for the specific activities and/or traits that were given in the example (see Table 1). Up to three content codes were permitted, although, as it turned out, almost none of the older students and no younger students 
required the use of the third content code. The content codes were grouped according to the stereotyping of the activity or trait (i.e., masculine, feminine, or neutral), based on past stereotyping research. A copy of the complete coding scheme may be obtained from the authors.

\begin{tabular}{|c|c|}
\hline \multicolumn{2}{|c|}{$\begin{array}{l}\text { Table } 1 \\
\text { Abbreviated Coding Scheme Description }\end{array}$} \\
\hline Category & Examples \\
\hline \multicolumn{2}{|l|}{ Feminine Stereotyped } \\
\hline Role Activities & Cooking, Taking care of children, Cleaning \\
\hline Appearance & Wearing make-up, petite, high voice \\
\hline Warmth/expressiveness & $\begin{array}{l}\text { Affectionate, overemotional, expresses } \\
\text { feelings }\end{array}$ \\
\hline Nonassertion (traits) & Crying, helpless, gullible \\
\hline Noninstrumental & Irrational, afraid of success \\
\hline \multicolumn{2}{|l|}{ Neutral } \\
\hline Role Activities & Playing (neutral) games \\
\hline Appearance & Professional appearance \\
\hline Social behaviors & Polite, responsible, fair \\
\hline Aggression & Revengeful \\
\hline Abilities & Clever, mature, diligent \\
\hline \multicolumn{2}{|l|}{ Masculine stereotyped } \\
\hline Role Activities & Employed, father, sports \\
\hline Appearance & Tall, deep voice, beard/mustache \\
\hline Nonexpressiveness & Unemotional, cool, stoic \\
\hline Aggression & $\begin{array}{l}\text { Physical fighting, verbal confrontation, } \\
\text { strong }\end{array}$ \\
\hline Instrumental & Ambitious, self-confident, being a leader \\
\hline
\end{tabular}

Raters were trained in the coding scheme, and then each answer was coded by two raters. Interrater agreement was $89 \%$ for the college students and $87 \%$ for the younger students, with disagreements resolved by discussion. 
Some of the participants had to be eliminated from further analyses because they gave no examples for either question that could be coded for content. There were 161 women and 119 men from the older sample and 87 girls and 6 boys from the younger sample who had at least one codeable answer in at least one category. One category of those eliminated were the 16 girls, 1 boy, 1 woman, and 1 man who either left the questions blank or had uncodeable answers, because of vagueness (e.g., "yesterday") or protests against the question ("What do you mean by 'like a boy.'") Another category was the 19 girls, 6 women, and 10 men who refused to answer because they felt they could not classify their behavior as masculine or feminine (e.g., "I don't recall ever acting exactly like a girl or a boy. I've always acted like me an individual.") There were also some participants (5 women, 7 men, 18 girls, and 7 boys) who refused to answer by stating that they were always like their sex and never like the other sex (e.g., a girl whose response to the masculine question was "I can't think that I ever did," and to the feminine question "I act like a girl everyday, all the time.") (See Signorella and Frieze, 1989, for other analyses on the older participants who refused to answer) Finally, there were two girls who gave counterstereotypic answers (e.g., "I always act like a boy" and "Never," to the masculine and feminine questions, respectively)

Because there were so few boys available, and so few with codeable responses, the boys' answers will not be discussed further.

\section{Results}

\section{Themes}

For the question about masculine behavior, there were only 10 women and 8 men who did not cite any examples. Four women and one man left the question blank, two women said they never acted that way, three men said they always acted that way, and four of each sex had uncodeable answers. Thus, there were remaining 151 women and 111 men who cited one or more codeable examples. Of those, $100 \%$ of the women and $99 \%$ of the men gave at least one stereotypic example.

Out of all the examples of masculine behavior cited, the most frequently used category for both men and women was aggression (40\% and 53\% for women and men, respectively), such as "A guy spilled beer on me and I slugged him." Second most frequent for both were masculine role activities ( $27 \%$ and $16 \%$ for women and men, respectively), such as ". . . playing in the mud or baseball or climbing trees." Third most frequent for both was 
instrumentality (10\% and $15 \%$ for women and men, respectively), such as ". . .I was tough, in charge, I didn't let other people change my mind. I got things done, and done effectively." Among the younger participants, there were six girls who did not cite examples. Two girls left the question blank, two said they never acted this way, and two had uncodeable answers. Thus, there were 81 girls who cited one or more instances of acting like a boy. Of these, $98 \%$ used at least one stereotypic example.

Girls' examples fell into two of the three frequently used categories by adults, although the most frequent (and dominant) category was masculine role activities (68\%), followed by aggression (14\%) Unlike the older participants', appearance was the third most frequent category used ( $8 \%$, e.g., ". . .I used to always have my hair cropped short. . .").

For the feminine question, there were 10 women and 15 men who did not cite any examples. Two women and five men left the question blank, nine men said they never acted this way, six women said they always act this way, and two women and one man had uncodeable answers. Thus, there were 151 women and 104 men who cited one or more codeable examples. Of these, $98 \%$ of the women and $91 \%$ of the men gave at least one stereotypic example.

The three most frequently used categories for both women and men were appearance (39\% and $11 \%$ for women and men, respectively; e.g., "I got an earring in my ear."), nonassertion (24\% and 34\% for women and men, respectively; e.g., "I backed down from a fight."), and warmth/expressivity ( $12 \%$ and $18 \%$ for women and men, respectively; e.g., "I helped my sister with a problem. My understanding was incredible.") Note, however, that on the feminine question women used the appearance category most frequently whereas men used the nonassertion most frequently. This differs from the masculine question, in which both men and women used the aggression category most frequently.

Among the younger participants, there were fewer examples cited. Among the 29 who did not give an example were four who left the question blank, two who said they never acted this way, nine who said they always acted this way, and 14 who had uncodeable answers (many, as noted earlier, were puzzled by the question) Thus, there were 58 girls who cited one or more examples of acting like a girl. Of these, $88 \%$ gave at least one stereotypic example. 
As with the women, the most frequently used category for girls was appearance (42\%; e.g., "When I wear a dress."). Unlike either of the adult groups, the second most frequently used category was feminine roles (28\%; e.g., I used to have a bunch of Barbie dolls. . ."). Tied for third in frequency of use were the categories of nonassertion and neutral roles (each 6\%).

\section{Gender of others present}

Table 2 displays the frequencies of examples given by female and male participants by the type of question and the gender of others present in the answer. First, men's, women's, and girls' descriptions of themselves acting in a feminine manner were compared (the top half of Table 2).

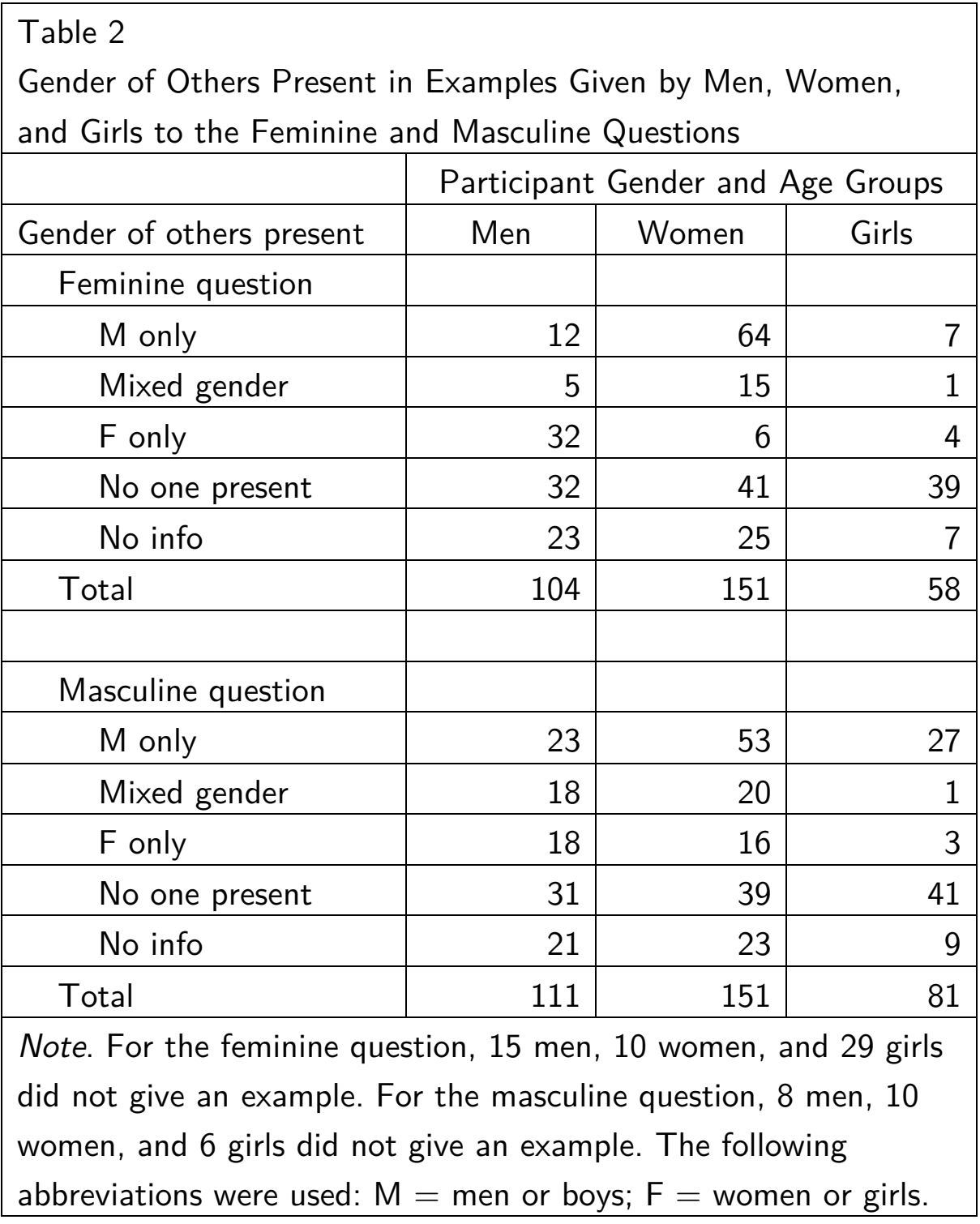


In order to test the hypothesis that girls or women would be more likely to mention men as being present in their feminine examples than would the men, the association between the participant groups and the gender of others present was assessed for those who identified the gender of others present (i.e., $\mathrm{F}$ only, both sexes, and $\mathrm{M}$ only cells) The association was significant, $\mathrm{X}^{2}(4, N=146)=52.4, p<.001$. The pattern of the association supports the hypothesis. Out of all examples in which there were others present and the gender of those present could be identified, both women's and girls' examples fell most frequently in the M-only-present category (75\% and $58 \%$, respectively) A typical example of this was "Wearing a formal gown, my hair done up, my boyfriend opening doors for me, wearing white gloves." Less frequent were examples with mixed gender (18\% and $8 \%$, respectively) or $\mathrm{F}$ only ( $7 \%$ and $33 \%$, respectively). Men were unlikely to cite examples in which $\mathrm{M}$ only were present $(24 \%)$

This same comparison shows support for another hypothesis; namely, that men would be more likely than women to mention girls or women being present for feminine behavior. As Table 2 indicates, men mentioned $\mathrm{F}$ only as present in $65 \%$ of the examples in which others were present and their gender could be identified, whereas women and girls mentioned $\mathrm{F}$ only as present in $5 \%$ and $33 \%$ of the examples, respectively.

We also examined the types of examples used for feminine behavior in relation to the gender of others present. For women, recall that the most frequent categories used were appearance and nonassertion. For both the appearance and nonassertion examples given by women, the pattern matched that observed on all feminine examples combined. Specifically, most of the examples were in the presence of $\mathrm{M}$ only $(74 \%$ and $75 \%$, for nonassertion and appearance, respectively) For men, the major category of example used for the feminine question was nonassertion, and the pattern for the nonassertion examples also matched that observed on all feminine examples combined. Specifically, more of the examples were with $\mathrm{F}$ only (58\%) than with M only $(27 \%)$ or mixed gender $(15 \%)$ There were not enough girls' examples to make the comparable comparison.

Next, women's and men's descriptions of themselves acting in a masculine manner in relation to the gender of others present were compared (the bottom half of Table 2) In order to test the hypothesis that men would be more likely to mention men or boys as being present in their masculine examples than would the female respondents, the association between the participant groups and the gender of others present was assessed for those who 
identified the gender of others present (i.e., the $\mathrm{F}$ only, mixed gender, and $\mathrm{M}$ only cells). The association was significant, $\mathrm{X}^{2}(4, N=179)=20.2, p<.001$, but not as we hypothesized. Although men's responses were slightly more frequently in the M-only-present category $(39 \%)$ than in the other two categories (31\% each), women's and girls' responses were even more predominantly in the M-only category (60\% and $87 \%$, respectively)

As with the feminine examples, we also examined use of individual themes in relation to the gender of others present. For all three participant groups, the two most commonly used masculine themes were aggression and roles, although girls differed from women and men in that they used roles more frequently than aggression. Unlike the comparison with feminine examples, the two masculine themes did not show the same patterns. When masculine roles were a theme, all three participant groups were more likely to mention $\mathrm{M}$ only as present (46\%, 68\%, and $96 \%$, for men, women, and girls, respectively) than to mention $\mathrm{F}$ only as present $(14 \%, 5 \%$, and $4 \%$, for men, women, and girls, respectively) When aggression was a theme, the tendency to cite $\mathrm{M}$ only, rather than $\mathrm{F}$ only, as present was much less pronounced. Among aggressive examples, men mentioned the presence of men or boys only $39 \%$ of the time versus the presence of women or girls only $33 \%$ of the time. Women mentioned $\mathrm{M}$ only as present $47 \%$ of the time versus $\mathrm{F}$ only as present $26 \%$ of the time. There were not enough examples among the girls to make this comparison.

Sexual/dating versus other contexts. To test the last hypothesis, the contexts used for the masculine and feminine examples were crosstabulated within sex (see Table 3). McNemar's Test (Siegal \& Castellan, 1988) was used to assess the change in use of contexts from the feminine to the masculine examples. Sexual/dating contexts were compared to other contexts. Because only one example was in a lesbian dating context, and thus would be expected to differ from the heterosexual dating examples, one woman had to be excluded from this comparison.

Women were expected to use a heterosexual dating context more frequently for feminine than for masculine examples, and this prediction was supported. Women used a heterosexual dating context $35 \%$ of the time for the feminine question versus $6.5 \%$ of the time for the masculine question, $\mathrm{X}^{2}(1, N=139)=29.6, p<.001$.

Contrary to prediction, men were also more likely to use a heterosexual dating context for the feminine question $(21 \%)$ than for the masculine question $(11 \%)$ However, this difference was of only borderline significance, $\mathrm{X}^{2}(1, N=100)=3.2, p<.10$. 


\begin{tabular}{|c|c|c|c|}
\hline \multicolumn{4}{|l|}{$\begin{array}{l}\text { Table } 3 \\
\text { Cross-Classification of } 1 \\
\text { Feminine Behaviors }\end{array}$} \\
\hline & \multicolumn{3}{|c|}{ Masculine Question } \\
\hline Women & Heterosexual Dating & Other & Total \\
\hline \multicolumn{4}{|l|}{ Feminine Question } \\
\hline Heterosexual Dating & 2 & 47 & 49 \\
\hline Other & 7 & 83 & 90 \\
\hline Total & 9 & 130 & 139 \\
\hline \multicolumn{4}{|l|}{ Men } \\
\hline \multicolumn{4}{|l|}{ Feminine Question } \\
\hline Heterosexual Dating & 2 & 17 & 19 \\
\hline Other & 8 & 63 & 71 \\
\hline Total & 10 & 80 & 90 \\
\hline \multicolumn{4}{|c|}{$\begin{array}{l}\text { Note. For the women's comparison, } 1 \text { whose example was in a lesbian dating context, } 10 \\
\text { who did not give a feminine example, } 10 \text { who did not give a masculine example, and } 1 \text { for } \\
\text { whom the context could not be determined were excluded. For the men's comparison, } 15 \\
\text { who did not give a feminine example, } 8 \text { who did not give a masculine example, and } 8 \text { for } \\
\text { whom the context could not be determined were excluded. }\end{array}$} \\
\hline
\end{tabular}

\section{Discussion}

The results from the open-ended questions about masculine and feminine behaviors showed first that most participants could cite examples of both feminine and masculine behaviors. Consistent with Spence's theory (e.g., 1993), individuals appear to display some characteristics associated with their own and the other gender.

The younger participants, while also able to cite many examples of same and other gender behaviors, displayed considerably more resistance to answering the questions. One possibility is that these responses represent the gender intensification sometimes hypothesized as occurring in adolescence (e.g., Katz and Ksansnak, 1994). To examine this, we looked at the association between grade and type of refusal to answer (nonstereotyped or stereotyped). There was some tendency for the youngest and the oldest adolescents to be the least stereotyped in their responses. They were less likely to give stereotyped answers 
and more likely to give nonstereotyped answers. This pattern might be interpreted as evidence for some gender intensification in midadolescence. However, on the other analyses there was no consistent tendency for the older participants to be more affected by the context (i.e., less consistently stereotyped). Whether gender intensification is observed in adolescence may also be affected by situational factors (e.g., see Alfieri, Ruble, \& Higgins, 1996).

As hypothesized, there were variations in the answers, discussed below, that supported the general contention that the display of masculine or feminine behaviors will vary according to the aspects of the context, including others present (Deaux \& Major, 1987).

The clearest support for the hypotheses was on the feminine question. Men, women, and girls responded as hypothesized, in that women and girls had a tendency to perform their feminine behaviors in the presence of men or boys, and men had a tendency to perform their feminine behaviors in the presence of women or girls. When women gave feminine examples, $50 \%$ of those examples mentioned only men or boys as being present, but just $5 \%$ of the examples included only women or girls. When men gave feminine examples and specified the gender of others present, $65 \%$ of those examples mentioned only women or girls as being present, compared to $24 \%$ in the M-only category.

The results for the masculine question did not support the hypotheses, nor did they parallel the results for the feminine question. All participant groups showed a tendency to mention men or boys only as present for masculine behaviors, although girls and women were significantly more likely to do so than were the men. However, this pattern appeared to be due primarily to the examples that included masculine role themes. As many of the role themes involved sports or "going out with the guys," such examples may be more prone to include men or boys only.

When the masculine examples were aggressive behaviors, both women and men responded more similarly, and with only a slight tendency to cite the presence of $\mathrm{M}$ only, rather than mixed gender or $\mathrm{F}$ only. There is a similar inconsistency in the findings from aggression research. Some authors have argued that aggression is likely to be performed in the presence of men (e.g., Deaux \& Major, 1987; Vrugt \& Kerkstra, 1984), and one meta-analysis of aggression research found that men were more likely to be the targets of aggression (Eagly \& Steffen, 1986) Another, more recent meta-analysis suggested that when provoked, both men and women show a tendency to aggress toward their own gender (Bettencourt \& 
Miller, 1996) Some of the examples given in the present research did speak to the issue of provocation and who was the target of the aggression (e.g., "When someone pushed me off a bus seat and I got so mad I kicked her and hit her."), but not enough to see if provocation is the factor determining whether the target of the aggression will be male or same gender. One possibility in future research would be to ask participants specifically for examples of aggressive behaviors. It would then be possible to examine some of the other context factors, such as the type of aggression or the presence of provocation, that might be important in affecting the display of aggressive behaviors.

Finally, women responded as predicted in their tendency to use a heterosexual dating context more frequently for feminine than masculine examples. Men were predicted to use a heterosexual dating context for masculine than feminine examples, but contrary to prediction, showed no difference in use of the heterosexual dating context between feminine and masculine examples. This finding suggests that for men, the presence of women may be more important in determining the display of feminine behaviors than whether the context is a heterosexual one. Women, on the other hand, responded differentially to the context more than to the gender of others present.

Taken together, the results suggest that the types of behaviors cited can vary depending on the context and the gender of others present. The open-ended procedures used in this study allowed us to more fully determine what factors may be associated with students' displays of feminine and masculine behaviors. One practical implication of these qualitative data is to further limit the descriptive labels attached to personality scales containing stereotypic "masculine" and "feminine" traits. Spence (e.g., 1991) has argued that the typical scales should be interpreted as assessing the personality traits they contain (i.e., instrumental and expressive traits), rather than some global characteristic such as masculinity-femininity or gender schema. The present data further support Spence's position. The predominant examples given in the present study were clearly not instrumental or expressive. Future research on characteristics stereotyped as "masculine" or "feminine" should focus instead on each characteristic as well as address situational variations in the display of these characteristics. 


\section{References}

Alfieri, T., Ruble, D.N,. and Higgins, E.T. (1996). Gender stereotypes during adolescence: developmental changes and the transition to junior high school. Developmental Psychology 32(6), 1129-1137. https://doi.org/ 10.1037//0012-1649.32.6.1129

Bettencourt, B. A., \& Miller, N. (1996). Gender differences in aggression as a function of provocation: A meta-analysis. Psychological Bulletin, 119(3), 422447. https://doi.org/10.1037/0033-2909.119.3.422

Davis, M., \& Weitz, S. (1981) Sex differences in body movements and positions. In C. Mayo \& N.M. Henley (Eds). Gender and Nonverbal Behavior. Springer-Verlag.

Deaux, K., \& Lewis, L. L. (1983) Assessment of gender stereotypes: Methodology and components, Psychological Documents, 13, 25. (Ms. 2583)

Deaux, K., \& Major, B. (1987). Putting gender into context: An interactive model of gender-related behavior. Psychological Review, 94(3), 369-389. https://doi.org/10.1037/0033-295X.94.3.369

Eagly, A. H., \& Steffen, V. J. (1986). Gender and aggressive behavior: A meta-analytic review of the social psychological literature. Psychological Bulletin, 100(3), 309330. https://doi.org/10.1037/0033-2909.100.3.309

Gilbert, L. A. (1994). Reclaiming and returning gender to context: Examples from studies of heterosexual dual-earner families. Psychology of Women Quarterly, 18(4), 539558. https://doi.org/10.1111/j.1471-6402.1994.tb01047.x

Jay, T.B. (1980) Sex roles and dirty word usage: A review of the literature and a reply to Haas, Psychological Bulletin, 88(3), 614-621. https://doi.org/10.1037/00332909.88.3.614

Katz, P. A., \& Ksansnak, K. R. (1994). Developmental aspects of gender role flexibility and traditionality in middle childhood and adolescence. Developmental Psychology, 30(2), 272-282. https://doi.org/10.1037/0012-1649.30.2.272

Liben, L. S., \& Signorella, M. L. (Eds.). (1987). New directions for child development, no. 38: Children's gender schemata. Jossey-Bass social and behavioral science series. San Francisco, CA, US: Jossey-Bass.

Mayo, C. and Henley, N.M. (1981) Nonverbal Behavior: Barrier or Agent For Social Change, in C. Mayo and N.M. Henley (eds), Gender and Nonverbal Behavior. New York: Springer-Verlag.

Pearson, J. C. (1985). Gender and Communication. Wm. C. Brown. 
Rasmussen, J. L., \& Moely, B. E. (1986) Impression formation as a function of the sex role appropriateness of linguistic behavior, Sex Roles, 14, 149-161. https://doi.org/10.1007/BF00288246

Ruble, D. N., \& Stangor, C. (1986). Stalking the elusive schema: Insights from developmental and social-psychological analyses of gender schemas. Social Cognition, 4(2), 227-261. https://doi.org/10.1521/soco.1986.4.2.227

Siegal, S., \& Castellan, N. J. (1988) Nonparametric statistics for the behavioral sciences $\left(2^{\text {nd }}\right.$ ed.). McGraw-Hill.

Signorella, M. L., \& Frieze, I. H. (1989) Gender schemas in college students, Psychology: A Journal of Human Behavior, 26(4), 17-22.

Signorella, M. L., Frieze, I. H., and Hershey, S.W. (1996) Single-sex versus mixed-sex classes and gender schemata in children and adolescents: A longitudinal comparison. Psychology of Women Quarterly, 20(4), 599-607. https://doi.org/10.1111/j.14716402.1996.tb00325.x

Spence, J. T. (1991). Do the BSRI and PAQ measure the same or different concepts? Psychology of Women Quarterly, 15(1), 141-165. https://doi.org/10.1111/j.1471-6402.1991.tb00483.x

Spence, J. T. (1993). Gender-related traits and gender ideology: Evidence for a multifactorial theory. Journal of Personality and Social Psychology, 64(4), 624635. https://doi.org/10.1037/0022-3514.64.4.624

Spence, J. T., \& Sawin, L. L. (1985). Images of masculinity and femininity: A reconceptualization. In V. F. O'Leary \& B. S. Wallston (Eds.). Women, gender, and social psychology (pp. 35-66). Erlbaum.

Unger, R. K. (1993). The personal is paradoxical: I. Feminists construct psychology. Feminism \& Psychology, 3(2), 211-218. https://doi.org/10.1177/0959353593032006

Vrugt, A., \& Kerkstra, A. (1984) Sex differences in nonverbal communication. Semiotica, 50(1-2), 1-41. https://doi.org/10.1515/semi.1984.50.1-2.1

Weitz, S. (1976) Sex differences in nonverbal communication. Sex Roles, 2, 175-184. https://doi.org/10.1007/BF00287250 